\title{
ASSOCIAÇÃO DE GLUTAMINA E PROBIÓTICOS NO TROFISMO MUCOSO DO CÓLON NA PERITONITE EXPERIMENTAL
}

\author{
ASSOCIATION OF GLUTAMINE AND PROBIOTICS ON THE COLONIC MUCOSAL \\ TROPHISM IN EXPERIMENTAL PERITONITIS
}

\author{
Wagner Marcondes da Cunha-Lopes, ACBC-MT ${ }^{1}$; José Eduardo de Aguilar-Nascimento, TCBC-MT2 \\ Diana Dock-Nascimento ${ }^{3}$; Maria Helena G. Gomes-da-Silva ${ }^{4}$; Victor de Albuquerque Teixeira da Silva ${ }^{5}$
}

\begin{abstract}
RESUMO: Objetivo: O objetivo deste estudo foi investigar o efeito da associação da glutamina e probióticos sobre a mucosa intestinal em ratos submetidos à peritonite experimental. Método: 16 ratos Wistar (250-350g) com peritonite experimental criada pelo método da punção dupla do ceco foram randomizados para receber diariamente no pós-operatório em conjunto com a dieta, a adição por gavagem de $0,500 \mathrm{~g}$ de glutamina e leite reconstituído, contendo probióticos $\left(10^{6}\right.$ unidades formadoras de colônias/g de Bifidobacterium lactis BL e Streptococcus thermophilus) (grupo glutamina-probióticos; $\mathrm{n}=8$ ) ou 0,495g de caseína e leite reconstituído sem probióticos (grupo controle; $\mathrm{n}=8$ ). O conteúdo das duas dietas foi isonitrogenado e isocalórico. Todos os animais foram sacrificados 120 horas após a peritonite experimental. A profundidade de criptas e espessura de parede da mucosa do cólon foram medidas em biopsias realizadas $2 \mathrm{~cm}$ acima da reflexão peritoneal. O restante da mucosa colônica foi pesado e nela mensurou-se o conteúdo de DNA. Resultados: Os animais que receberam glutamina e probióticos apresentaram mucosa mais pesada $(0,49 \pm 0,12$ vs. $0,42 \pm 0,07 \mathrm{~g} ; \mathrm{p}=0,02)$, maior conteúdo de DNA $(0,31 \pm 0,07$ vs. $0,22 \pm 0,05 \mathrm{mg} / \mathrm{g}$ de tecido; $\mathrm{p}<0,01)$ e criptas mais profundas $(272 \pm 51$ vs. $311 \pm 39 \mu ; \mathrm{p}=0,04)$ que o grupo controle. Conclusão: A associação da glutamina e probióticos confere um maior trofismo na mucosa colônica em ratos submetidos à peritonite experimental (Rev. Col. Bras. Cir. 2007; 34(1): 48-53).
\end{abstract}

Descritores: Peritonite; Ratos Wistar; Probióticos; Glutamina; Mucosa intestinal; Cólon.

\section{INTRODUÇÃO}

Apesar dos avanços no diagnóstico, técnica operatória, terapêutica antimicrobiana e cuidados intensivos, a peritonite secundária grave permanece como uma doença potencialmente fatal, com mortalidade estimada em um terço dos pacientes acometidos ${ }^{1,2}$. A integridade estrutural e funcional das mucosas constitui um fator protetor importante contra o fenômeno da translocação bacteriana ${ }^{3}$, definida como a passagem das bactérias do lúmen entérico, através da barreira intestinal, para os tecidos previamente estéreis, tais como linfonodos, fígado, baço e sangue ${ }^{3,4}$. Há evidências de uma associação entre translocação bacteriana e sepse em pacientes cirúrgicos ${ }^{5}$. Este fenômeno é o principal fator para a eclosão da sepse, do choque, da síndrome da resposta inflamatória sistêmica e, conseqüente síndrome da disfunção de múltiplos órgãos ${ }^{4-6}$.

Estudos randomizados nos últimos anos têm reforçado o papel da dieta suplementada com glutamina nos pacientes graves. Em pacientes cirúrgicos, esta suplementação tem sido associada à redução de complicações infecciosas e à diminuição do tempo de permanência hospitalar, sem a diminuição do índice de mortalidade ${ }^{7,8}$. Aguilar-Nascimento et al. comprovaram que a infusão intraluminal de glutamina diminui a injúria à mucosa e a acumulação neutrofílica na submucosa ${ }^{9}$.

A estimulação da mucosa e do sistema imunológico do hospedeiro pelos probióticos foi evidenciada em estudos com animais ${ }^{10}$. Esta estimulação ocorre a partir da capacidade de adesão dos microorganismos às células intestinais e de interação com o sistema do tecido linfóide associado ao intestino ${ }^{11,12}$. A estimulação do sistema imunológico inato em pessoas saudáveis que receberam Bifidobacterium lactis, estimula a capacidade de fagocitose das células polimorfonucleares ${ }^{13}$. Em peritonite existe pouca comprovação experimental de possível ação benéfica de probióticos em peritonite grave ${ }^{14}$.

A glutamina como nutriente da mucosa e o probiótico como modulador da flora bacteriana podem ter ação sinérgica. A ação da glutamina na nutrição da mucosa intestinal e nas células do sistema imunológico, diminuindo a apoptose, mantendo o trofismo e dificultando a passagem de bactérias através da mucosa, associado a manutenção de flora intestinal pelos probióticos, dificultando a entrada de bactérias deletérias ao organismo podem trazer benefícios para o paciente. Em resumo, esse conjunto de ações pode teoricamente diminuir a ocorrência de translocação bacteriana, a incidência de

\footnotetext{
1. Mestrando do Curso de Pós-Graduação em Ciências da Saúde da Faculdade de Ciências Médicas da Universidade Federal de Mato Grosso.

2. Professor Titular do Departamento de Clínica Cirúrgica da Faculdade de Ciências Médicas da Universidade Federal de Mato Grosso.

3. Professor Assistente do Departamento de Alimentos e Nutrição da Faculdade de Nutrição da Universidade Federal de Mato Grosso.

4. Professor Adjunto do Departamento de Alimentos e Nutrição da Faculdade de Nutrição da Universidade Federal de Mato Grosso.

5. Acadêmico de Medicina da Universidade de Cuiabá.

Recebido em 15/08/06

Aceito para publicação 01/09/06
}

Conflito de interesses:

Fonte de financiamento: nenhuma

Trabalho realizado no Departamento de Clínica Cirúrgica da Faculdade de Ciências Médicas da Universidade Federal de Mato Grosso. 
infecção e ainda manter a integridade da barreira intestinal ${ }^{9,15}$. Nesse contexto, Falcão-de-Arruda e Aguilar-Nascimento, em estudo com 23 pacientes internados em UTI com trauma craniano observaram menor taxa de infecção e diminuição da permanência em UTI com a associação de glutamina com probióticos acrescida à dieta ${ }^{15}$. Não foram encontrados na literatura trabalhos que avaliaram um possível efeito protetor conjunto da glutamina e probióticos na manutenção do trofismo intestinal em peritonite experimental. Dessa forma, é relevante a investigação do uso dessa associação em modelo animal de peritonite para investigar os possíveis benefícios na mucosa colônica. Assim, o presente estudo teve como objetivo investigar o efeito da associação da glutamina e probióticos sobre o trofismo da mucosa colônica em ratos submetidos à peritonite experimental.

\section{MÉTODOS}

Foram estudados 16 ratos machos da raça Wistar (Rattus norvergicus, variedade albinos, ordem Rodentia mammalia, família Muridae), com peso entre 250-350g provenientes do Biotério Central da UFMT. O experimento seguiu as determinações do COBEA (Colégio Brasileiro de Experimentação Animal), padronizadas pela Universidade Federal de Mato Grosso. Os animais ficaram 10 dias no laboratório, sob temperatura de $25^{\circ} \mathrm{C}$, para aclimatação em ciclos de 12 horas de claro/escuro, alimentados ad libitum com ração padrão de laboratório (Ração Labina, Agribrands-Purina Ltda, Paulínia, SP, Brasil). Os animais foram sorteados para dois grupos de oito animais cada, conforme descrito abaixo. Todos os animais foram anestesiados por via inalatória com éter e submetidos à laparotomia mediana de aproximadamente $3 \mathrm{~cm}$ após jejum pré-operatório de oito horas antes do procedimento. Após identificação do ceco-apêndice, realizou-se nesse local dupla perfuração com agulha $12 \times 8$ provocando-se uma contaminação da cavidade intestinal com conteúdo fecal (CLP). A seguir, procedeu-se a invaginação da lesão e fechamento em bolsa de tabaco com fio de nylon 4.0, segundo modelo experimental padronizado ${ }^{16,17}$.Um estudo piloto antes da cole- ta de dados mostrou que a CLP com bolsa em tabaco produzia uma peritonite adequada e com baixa mortalidade nos primeiros cinco dias de pós-operatório.

No pós-operatório, os animais receberam água $a d$ libitum e foram realimentados após 48 horas com a mesma dieta descrita acima. Foram então randomizados para receber além da dieta, uma adição diária de $500 \mathrm{~g}$ ( 2,50g/kg de peso) de glutamina (Glutamin, Kasdorf SA, Garín, Argentina) e leite reconstituído contendo probióticos $(4 \mathrm{~g} / \mathrm{dia}$ de leite reconstituído contendo $10^{6}$ unidades formadoras de colônias [UFC] /g de Bifidobacterium lactis BL e Streptococcus thermophilus; NAN-2 Probiótico, Nestlé, São Paulo, Brasil) (grupo glutamina-probióticos; GGP, $n=8$ ) ou a mesma dieta acrescida de $495 \mathrm{~g}$ de caseína (Maxipro, Nuteral, Fortaleza-Ceará, Brasil) e leite reconstituído sem probióticos (4g/dia de leite NAN-2, Nestlé, São Paulo, Brasil) (grupo controle; GC, $\mathrm{n}=8$ ). A Tabela 1 mostra o conteúdo isonitrogenado e isocalórico das duas dietas.

A administração de glutamina e probióticos (GGP) ou caseína e leite (GC) foi feita por gavagem em duas tomadas diárias, as 6 e 18 horas. Cada gavagem continha $250 \mathrm{~g}$ de glutamina (250g de Glutamin) e $2 \mathrm{~g}$ de leite contendo probióticos no GPG, ou $250 \mathrm{~g}$ de caseína (275g de Maxipro) e $2 \mathrm{~g}$ de leite sem probióticos para o grupo controle, ambas dissolvidas em até $2 \mathrm{~mL}$ de água destilada.

Todos os animais foram sacrificados 120 horas após a operação que criou a peritonite experimental. Na necrópsia de cada animal, colhia-se $2 \mathrm{~cm}$ de íleo terminal a partir de $1 \mathrm{~cm}$ proximal à válvula ileocecal e $2 \mathrm{~cm}$ de cólon sigmóide a partir de $1 \mathrm{~cm}$ proximal à reflexão peritoneal, ambos livres do mesentério e mesocólon correspondente. Estas peças foram fixadas em papel cartão e inseridas em frascos com formol a $10 \%$. No laboratório foram preparadas lâminas a partir de cortes sagitais de $4 \mathrm{~mm}$ cada, fixados em parafina e corados com hematoxilina-eosina. Um observador que desconhecia o desenho do estudo realizou medidas micrométricas da profundidade de criptas e espessura de parede da mucosa do cólon em cada animal, com auxílio de régua micrométrica (Olympus, Japão). Cada animal foi representado pela média de cinco medi-

Tabela 1 - Composição das dietas utilizadas na alimentação dos grupos Glutamina-Probiótico e Controle.

\begin{tabular}{lccc}
\hline Composição & \multicolumn{3}{c}{ Dietas Utilizadas } \\
\cline { 2 - 4 } & Padrão* $^{*}$ & Glutamina-Probiótico & Controle \\
\hline Carboidratos (g) & 7,75 & 10,0 & 10,0 \\
Lipídios (g) $_{\text {Caseína }}$ & 0,8 & 1,65 & 1,66 \\
Glutamina $^{\mathbb{I I}}$ & - & - & 0,50 \\
Proteínas (g) $_{\text {Probióticos (colônias) }}^{\dagger}$ & - & 0,50 & - \\
Calorias (kcal) $_{\text {Peso total (g) }}^{4,6}$ & 0 & 5,74 & 5,74 \\
\hline
\end{tabular}

*Ração Labina, Purina,São Paulo

$\dagger$ NAN 2 Probiótico, Nestlé;

+ Maxpro, Nuteral, Nutricia, Fortaleza

Il Glutamin, Kasdorf SA, Garín, Argentina 
das realizadas nas glândulas melhores orientadas ${ }^{18}$. Todo cólon foi ressecado a partir da válvula ileocecal até a reflexão peritoneal. Neste segmento, a mucosa foi raspada com lamina de vidro, pesada, identificada, e armazenada em frascos de polietileno em freezer à $-18^{\circ} \mathrm{C}$ para medida do conteúdo de DNA. O DNA foi mensurado pelo método da difenilamina ${ }^{19,20}$.

\section{MÉTODO ESTATÍSTICO}

Utilizou-se o teste $t$ de Student para comparação entre os grupos visto que havia normalidade (teste de Kolgomorov-Smirnov) e homogeneidade (teste de Levene) das amostras. O nível de significância adotado para rejeição da hipótese de nulidade foi de $5 \%(p=0,05)$. Os resultados foram apontados como média e desvio padrão. Todas as análises foram feitas com o pacote estatístico SPSS for Windows 11.0 (Stat Soft, Inc., Tulsa, Oklahoma, EUA).

\section{RESULTADOS}

Não houve mortalidade durante o estudo. Observouse no exame da cavidade abdominal que todos os animais apresentavam sinais de peritonite com secreção purulenta e aderência entre órgãos.

\section{Peso da mucosa do cólon}

A mucosa dos animais que receberam glutamina e probióticos $(0,49 \pm 0,12 \mathrm{~g})$ apresentou-se estatisticamente mais pesada $(p=0,02)$ que a dos animais controles $(0,42 \pm 0,07 \mathrm{~g})(\mathrm{Fi}-$ gura 1).

\section{Conteúdo de DNA na mucosa do cólon}

Os ratos alimentados com probióticos e glutamina apresentaram conteúdo de DNA maior que os controles $(0,31 \pm 0,07$ vs $0,22 \pm 0,05 \mathrm{mg} / \mathrm{g}$ de tecido; $p<0,01)$ (Figura 2).

\section{Profundidade de criptas do cólon}

As criptas colônicas no grupo GGP $(272 \pm 51 \mu)$ apresentaram-se mais profundas $(p=0,04)$ que no grupo controle $(311 \pm 39 \mu)($ Figura 3).

\section{Espessura da parede do cólon}

Não houve diferença na espessura da parede colônica entre os grupos $(\mathrm{GGP}=553 \pm 61$ vs. $\mathrm{GC}=533 \pm 54 \mu ; \mathrm{p}=0,52)$

\section{DISCUSSÃo}

A análise global dos resultados mostrou que a adição de probióticos e glutamina na dieta de animais com peritonite associou-se a melhor trofismo mucoso no cólon. Isso foi verificado tanto pelo maior conteúdo do DNA da mucosa colônica, quanto nas medidas físicas de peso da mucosa do cólon, e histomorfométricas da profundidade das criptas colônicas. Esses dados são consistentes com outros estudos experimentais, em que a glutamina apresentou ação positiva sobre a manutenção da mucosa colônica em situações adversas como radiação ${ }^{21}$, uso de nutrição parenteral ${ }^{22} \mathrm{e}$ com outras pesquisas em que a glutamina, apesar de ser o

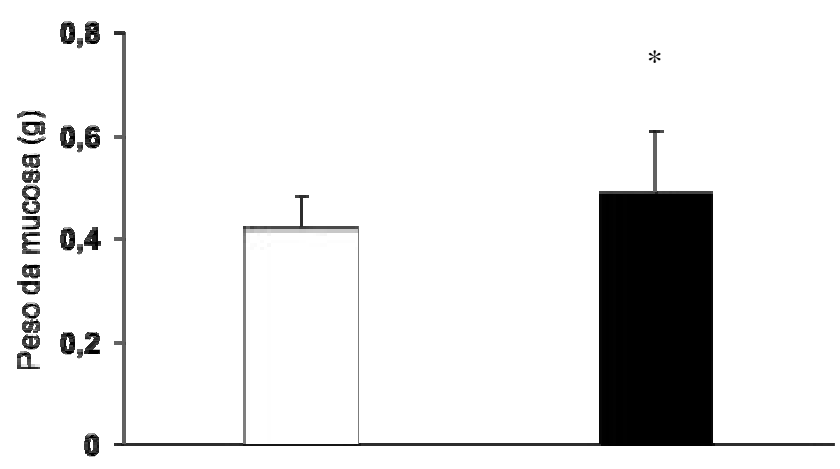

Figura 1 - Peso da mucosa do cólon segundo grupo. Grupo controle (branco); Grupo glutamina-probiótico (negro). Dados expressam a média e desvio padrão.

$* p=0,02$ versus grupo controle.

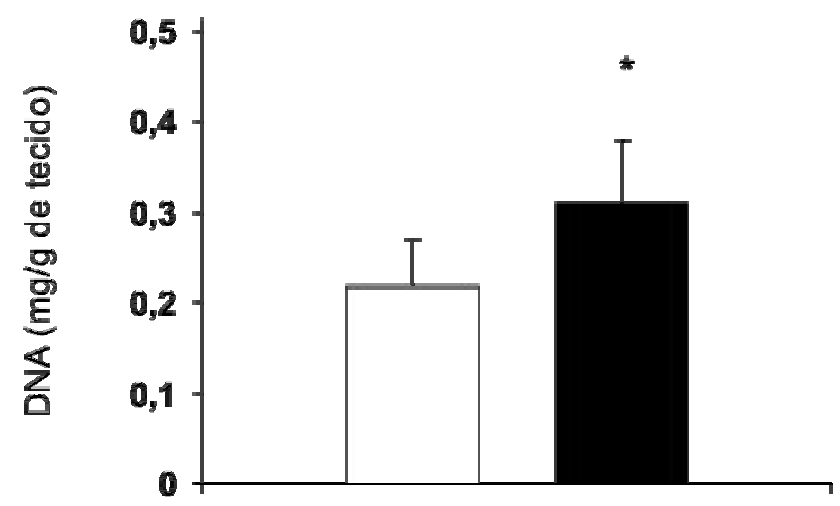

Figura 2 - Conteúdo de DNA da mucosa do cólon segundo grupo. Grupo controle (branco); Grupo glutamina-probiótico (negro). Dados expressam a média e desvio padrão.

$* p<0,01$ versus grupo controle.

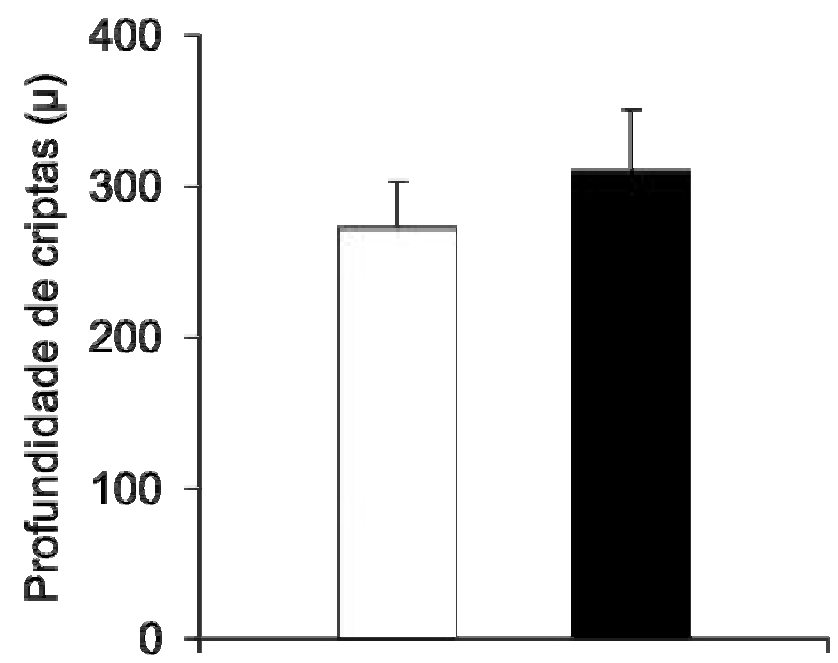

Figura 3 - Profundidade das criptas do cólon segundo grupo. Grupo controle (branco); Grupo glutamina-probiótico (negro). Dados expressam a média e desvio padrão.

$* p=0,04$ versus grupo controle.

principal nutriente do enterócito, promove ações semelhantes no cólon, especialmente em situações de lesão intestinal ${ }^{21-23}$. A ação dos probióticos como auxiliares na produção de áci- 
dos graxos de cadeia curta (AGCC) a partir de material existente na luz explica os achados tróficos mais significativos no grupo da dieta em estudo ${ }^{12,18}$.

Nos dois primeiros dias após o estresse metabólico, o consumo de glutamina aumenta drasticamente. Kapadia et al. encontraram em modelo animal, níveis plasmáticos e musculares de glutamina diminuídos em 30 e $50 \%$, nas 24 e 48 horas após a laparotomia, respectivamente ${ }^{25}$. Portanto, é provável que a quantidade de glutamina ofertada aos ratos durante o experimento, não tenha suprido suas necessidades metabólicas aumentadas no período de catabolismo intenso a que foram submetidos. Após as 48 horas do início do trauma os animais já apresentavam uma resposta inflamatória sistêmica menos exacerbada, e assim, as necessidades metabólicas de glutamina ficaram diminuídas e esta pode ser liberada para uso pelos enterócitos.

Em quadro de instabilidade hemodinâmica, a alimentação enteral precoce pode ser maléfica pelo comprometimento do fluxo esplâncnico ${ }^{26}$, como ocorre na presença de peritonite. No entanto, em enterocolite experimental, o uso parenteral de glutamina parece suprir as necessidades da mucosa intestinal durante jejum prolongado ao incrementar o peso da mucosa, a altura dos vilos e o conteúdo de $\mathrm{DNA}^{27}$. Alguns estudos têm assinalado que a glutamina não é eficaz para uso enteral devido a sua instabilidade ao calor e a dificuldade de homogeneização em soluções líquidas ${ }^{27}$. Por ser considerado não essencial e por ter um tempo de vida útil limitado, esse aminoácido não é incluído nas fórmulas padronizadas. Apesar disso, tanto a L-glutamina como suplemento alimentar e os dipeptídeos estáveis da glutamina são muito utilizados ${ }^{7}$. Se administrada de forma enteral, a glutamina diminui a injúria da mucosa em situações de isquemia e reperfusão e de trauma ${ }^{24,28}$. De qualquer forma, a glutamina administrada via enteral aumenta a altura de vilos e o conteúdo de nitrogênio na mucosa e estimula o crescimento da mucosa ${ }^{29}$. Assim, a glutamina ministrada tanto na forma enteral como parenteral tem efeito benéfico e trófico na mucosa intestinal, tanto de ratos quanto de humanos ${ }^{30}$.

A realimentação com glutamina teve como finalidade fornecer substrato energético ao enterócito, bem como às células de defesa, para prevenir a atrofia da mucosa intestinal. Sabe-se que a atrofia da mucosa intestinal ocorre devido à falta do estímulo funcional e a ausência das secreções ${ }^{30-31}$, e que a diminuição na irrigação intestinal e a falta de suporte nutricional são os dois fatores mais importantes na destruição da barreira intestinal ${ }^{3,32}$. Nesse estudo, as dietas foram pesadas e homogeneizadas em conteúdos isocalóricos e isonitrogenados, minutos antes da ministração para assegurar que cada animal recebesse realmente sua cota diária. $\mathrm{O}$ curto período de tempo entre a preparação da dieta e a ingestão assegurou a estabilidade dos nutrientes até sua chegada à luz intestinal.

A CLP foi o modelo experimental de peritonite utilizado no presente estudo, pelo fato de que nesse modelo a contaminação ocorre com as próprias bactérias da luz intestinal do rato assemelhando-se com a ocorrência de uma peritonite secundária. Assim, a CLP tem sido amplamente empregada e induz a peritonite, embasando a escolha adequada do método ${ }^{16,17}$, que induziu peritonite bacteriana com baixa mortalidade e possibilitou a avaliação dos efeitos das duas dietas na vigência de estresse infeccioso intra-abdominal. Com o estudo piloto, verificou-se que a adição da bolsa de tabaco ao modelo, reduzia o grau de contaminação e assim, produzia um modelo anima de peritonite com baixa mortalidade e adequado aos propósitos do trabalho. No entanto, a CLP é um modelo que induz a uma peritonite sem o controle de outros modelos nos quais a concentração e o tipo de bactéria introduzidos na cavidade peritoneal são conhecidos $^{33}$.

Devido ao rápido turnover da mucosa intestinal, um curto período de jejum pode proporcionar atrofia da mucosa colônica. Nesse aspecto, o efeito dos probióticos no trofismo da mucosa intestinal de ratos já foi comprovado por outros pesquisadores ${ }^{12}$. Dock, Aguilar-Nascimento e Latorraca demonstraram melhor recuperação do trofismo da mucosa intestinal de ratos submetidos à desnutrição crônica ${ }^{33}$ e aguda $^{12}$ associada à adição de probióticos a dieta dos animais. Foligne et al. comprovaram que três dias de dieta suplementada com iogurte estimulam uma série de parâmetros tróficos no intestino delgado de ratos em condições basais, porém estas mudanças não foram vistas após duas semanas de tratamento ${ }^{34}$. Os probióticos apresentam diversos mecanismos de ação, como antagonismo contra patógenos, efeito trófico nas mucosas, imunoestimulação do hospedeiro e inibição da produção de toxinas bacterianas ${ }^{11-14}$. Desta forma, podem até evitar o aparecimento de resistência por parte das bactérias patógenas.

A falta de um grupo de controle constituído de animais operados, porém, sem a criação de peritonite é fator limitante no estudo porém não invalida as conclusões do trabalho. Os dois grupos de comparação utilizaram dietas iso-calóricas e iso-nitrogenadas e foram submetidos ao mesmo modelo de peritonite. Embora a não existência de grupos específicos de tratamento apenas com glutamina ou apenas com probióticos possa metodologicamente também limitar o trabalho, o objetivo do estudo era o de investigar a associação da glutamina com probióticos e testar seus sinérgicos efeitos via diferentes ações indiretamente tróficas à mucosa intestinal ${ }^{9,10,12-14}$. Com efeito, os benefícios clínicos dessa associação em pacientes com trauma crânio-encefálicos já foram demonstrados anteriormente ${ }^{15}$. Falcão-de-Arruda e Aguilar-Nascimento comprovaram em estudo com humanos que o uso combinado de glutamina e probióticos na alimentação enteral de pacientes vítimas de traumatismo crânio-encefálico reduz significativamente a incidência de infecção ${ }^{15}$. A hipótese central do atual estudo foi baseada no uso da combinação glutamina e probióticos que visou tanto o fornecimento energético para a mucosa intestinal e células do sistema imune, bem como ação sobre a flora patogênica de forma a diminuir a possibilidade de translocação bacteriana.

A análise dos resultados permite concluir que a associação da glutamina e probióticos confere um maior trofismo na mucosa colônica em ratos submetidos à peritonite bacteriana. 


\begin{abstract}
Background: The aim of this study was to investigate the effect of the association of glutamine and probiotics on the colonic mucosal trophism in experimental peritonitis. Method: 16 Wistar rats (250-350g) with experimental peritonitis created by double cecal puncture were randomized to receive, postoperatively in addition to rat chow, daily gavages of either 0,500g of glutamine and reconstituted milk containing probiotics $\left(10^{6}\right.$ colony-forming units/g of Bifidobacterium lactis BL and Streptococcus thermophilus) (glutamine-probiotics group; $n=8$ ) or $0.495 \mathrm{~g}$ of caseine and reconstituted milk without probiotics (control group; $n=8)$. The contents of the two diets were isonitrogenous and isocaloric. All animals were killed $120 \mathrm{~h}$ after the creation of the peritonitis. Crypt depth and wall width of the colonic mucosa were registered in biopsies taken $2 \mathrm{~cm}$ above peritoneal reflexion. The rest of the colonic mucosa was weighted and assayed for DNA content. Results: Animals receiving glutamine ans probióticos presented greater mucosal weight $(0,49 \pm 0,12 \mathrm{vs.} 0.42 \pm 0.07 \mathrm{~g} ; \mathrm{p}=0.02)$, DNA content $(0.31 \pm 0.07 \mathrm{vs} 0.22 \pm 0.05$ $\mathrm{mg} / \mathrm{g}$ tissue weigh, $p<0.01)$ e deeper crypts $(272 \pm 51$ vs. $311 \pm 39 \mu ; p=0,04)$ than controls. Conclusion: The association of glutamine and probiotics enhances colonic mucosal trophism in rats under experimental peritonitis.
\end{abstract}

Key words: Peritonitis; Rats, Wistar; Probiotics: Glutamine; Intestinal mucosa; Colon.

\section{REFERÊNCIAS}

1. Laroche M, Harding G. Primary and secondary peritonitis: an update. Eur J Clin Microbiol Infect Dis. 1998;17(8):542-50.

2. Wittmann DH, Schein M, Condon RE. Management of secondary peritonitis. Ann Surg. 1996;224(1):10-8.

3. Ding LA, Li JS. Gut in diseases: physiological elements and their clinical significance. World J Gastroenterol. 2003;9(11):2385-9.

4. Guarner F, Malagelada JR. Gut flora in health and disease. Lancet. 2003; 361(9356):512-9.

5. O'Boyle CJ, MacFie J, Mitchell CJ, Johnstone D, Sagar PM, Sedman PC. Microbiology of bacterial translocation in humans. Gut. 1998; 42(1):29-35.

6. Lichtman SM. Bacterial translocation in humans. J Pediatr Gastroenterol Nutr. 2001;33(1):1-10.

7. Labow BI, Souba WW. Glutamine. World J Surg. 2000;24(12):1503-13.

8. Novak F, Heyland DK, Avenell A, Drover JW, Su X. Glutamine supplementation in serious illness: a systematic review of the evidence. Crit Care Med. 2002;30(9):2022-9.

9. Aguilar-Nascimento JE, Marques CG, Mariano AC, Salomão $\mathrm{AB}$, Neves JS. Benefits of intraluminal injection of glutamine for intestinal mucosa during ischemia-referfusion. Eur Surg Res. 2003;35(4):352-6.

10. Meydani SN, Ha WK. Immunologic effects of yogurt. Am J Clin Nutr. 2000; 71(4):861-72.

11. Lu L, Walker WA. Pathologic and physiologic interactions of bacteria with the gastrointestinal epithelium. Am J Clin Nutr. 2001;73(6):1124-30.

12. Dock DB, Latorraca MQ, Aguilar-Nascimento JE, Silva MHG. Probiotics enhance recovery from malnutrition and lessen colonic mucosal atrophy after short-term fasting in rats. Nutrition. 2004;20(5):473-6.

13. Arunachalam K, Gill HS, Chandra RK. Enhancement of natural immune function by dietary consumption of Bifidobacterium lactis (HN019). Eur J Clin Nutr. 2000;54(3):263-7.

14. Tsunoda A, Shibusawa M, Tsunoda Y, Watanabe M, Nomoto K, Kusano M. Effect of Lactobacillus casei on a novel murine model of abdominal sepsis. J Surg Res. 2002;107(1):37-43.

15. Arruda ISF, Aguilar-Nascimento JE. Benefits of early enteral nutrition with glutamine and probiotics in brain injury patients. Clin Sci. 2004; 10693):287-92.

16. Salgado Jr W, Cunha FQ, Sankarankuty AS, Santos JS. Desenvolvimento de modelo de peritonite bacteriana para avaliação do tratamento mediante acesso laparotômico e video-laparoscópico. Acta Cir Bras. 2001;16(1):9-12.
17. Maier S, Traeger T, Entleutner M, Westerholt A, Kleist B, Huser N, Holzmann B, Stier A, Pfeffer K, Heidecke CD. Cecal ligation and puncture versus colon ascendens stent peritonitis: two distinct animal models for polymicrobial sepsis. Shock. 2004;21(6):505-11.

18. Aguilar-Nascimento JE, Oliveira-Neto JP, Mathie RT, Williamson RC. Effect of intraoperative nutritional solutions on perianastomotic colonic mucosa in experimental large bowel obstruction. Dig Dis Sci.1997;42(12):2581- 4.

19. Gyles KW, Myers A. An improved diphenylamine method for the estimation of desoxyribonucleic acid [letter]. Nature. 1965;206(4979):93.

20. Aguilar-Nascimento JE, Silva LRF, Oliveira AF, Silva MHG. Enhanced mucosal re-epithelialization induced by short chain fatty acids in experimental colitis. Braz J Med Biol Res. 1999;32(8):961-6.

21. Diestel CF, Lopes-Paulo F, Marques RG, Horst NL, Caetano CE. [Effect of oral supplement of I-glutamine in colonic wall of rats subjected to abdominal irradiation.] Acta Cir Bras. 2005;20(Suppl 1):94-100. Epub 2005 Aug 23.

22. Mandir N, Goodlad RA. The effects of glutamine on intestinal epithelial cell proliferation in parenterally fed rats. Gut. 1999;44(5):608-14.

23. Souba WW, Smith RJ, Wilmore DW. Glutamine metabolism by the intestinal tract. JPEN J Parenter Enteral Nutr. 1985;9(5):60817.

24. Souba WW, Klimberg VS, Plumley DA, Salloum RM, Flynn TC, Bland KI, Copeland EM 3rd. The role of glutamine in maintaining a healthy gut and supporting the metabolic response to injury and infection. J Surg Res. 1990; 48(4):38391.

25. Kapadia CR, Colpoys MF, Jiang ZM, Johnson DJ, Smith RJ, Wilmore DW. Maintenance of skeletal muscle intracellular glutamine during standard surgical trauma. JPEN J Parenter Enteral Nutr. 1985;9(5):583-9.

26. Aguilar-Nascimento JE. The role of macronutrients in gastrointestinal blood flow. Curr Opin Clin Nutr Metab Care. 2005;8(5):552-6.

27. Inoue Y, Grant JP, Snyder PJ. Effect of glutamine-supplemented total parenteral nutrition on recovery of the small intestine after starvation atrophy. JPEN J Parenter Enteral Nutr. 1993;17(2):165-70

28. Aguilar-Nascimento JE, Marques CG, Mariano AC, Salomão $\mathrm{AB}$, Neves JS. Benefits of intraluminal injection of glutamine for intestinal mucosa during ischemia-reperfusion. Eur Surg Res. 2003;35(4):352-6. 
29. Duggan C, Gannon J, Walker WA. Protective nutrients and functional foods for the gastrointestinal tract. Am J Clin Nutr. 2002;75(5):789-808.

30. MacFie J. Enteral versus parenteral nutrition: the significance of bacterial translocation and gut-barrier function. Nutrition. 2000;16(7-8):606-11.

31. Foitzik T, Kruschewski M, Kroesen AJ, Hotz HG, Eibl G, Buhr HJ. Does glutamine reduce bacterial translocation? A study in two animal models with impaired gut barrier. Int J Colorectal Dis. 1999;14(3):143-9.

32. Spadoni JM, Aguilar-Nascimento JE, Silva MH, Spadoni Neto B, Costa PA, Alessio DM. Effects of the combined use of glutamine and growth hormone in the intestinal adaptation after massive resection of the small bowel in rats. Acta Cir Bras. 2005;20(5):382-9. Epub 2005 Sep 5.

33. Dock DB, Aguilar-Nascimento JE, Latorraca MQ. Probiotics enhance the recovery of gut atrophy in experimental malnutrition. Biocell. 2004;28(2):143-50.
34. Foligne B, Sénegás-Balas F, Antoine JM, Cayuela C, RolfPedersen N, Balas D. Trophic status of the small intestine in young and aged rats: modulation by a yogurt-supplemented diet. Dig Dis Sci. 2004;49(7-8):1291-301.

Como citar este artigo:

Lopes WMC, Aguilar-Nascimento JE, Nascimento DD, Silva MHG Silva VAT. Associação de glutamina e probióticos no trofismo mucoso do cólon na peritonite experimental. Rev Col Bras Cir. [periódico na internet] 2007;34(1). Disponível em URL: http://www.scielo.br/rcbc

Endereço para correspondência:

Professor José Eduardo de Aguilar Nascimento

Rua Estevão de Mendonça 81 apto 801

78043-200 - Cuiabá - MT

Tel: 6536237183 Celular: 65 99815388; Fax: 6536234020

E-mail: aguilar@terra.com.br 